\title{
Subclinical cardiac dysfunction in acromegaly: evidence for a specific disease of heart muscle
}

\author{
ERWIN A RODRIGUES, MICHAEL P CARUANA, AVIJIT LAHIRI, \\ J D N NABARRO, * HOWARD S JACOBS, * EDWARD B RAFTERY
}

From the Department of Cardiology and Division of Clinical Sciences, Northwick Park Hospital and Clinical Research Centre, Harrow, and the ${ }^{\star}$ Middlesex Hospital, London

SUMMARY Acromegaly is associated with an increased cardiac morbidity and mortality, but it is not clear whether this is the result of increased incidence of hypertension and coronary heart disease or of a specific disease of heart muscle. Thirty four acromegalic patients were studied by non-invasive techniques. Seven of these patients had raised plasma concentrations of growth hormone at the time of study; three were newly diagnosed and had not received any treatment. Hypertension was present in nine $(26 \%)$ but only three (9\%) had electrocardiographic left ventricular hypertrophy. Echocardiography showed ventricular hypertrophy in $12(48 \%)$ and increased left ventricular mass in $17(68 \%)$ patients. Holter monitoring detected important ventricular arrhythmias in 14 patients. Thallium-201 scanning showed evidence for coronary heart disease in eight patients. Systolic time intervals were normal except when there was coexistent ischaemic heart disease. A comparison between 19 acromegalic patients with no other detectable cause of heart disease and 22 age matched controls showed appreciably abnormal left ventricular diastolic function in the group with acromegaly. The abnormalities shown did not correlate with left ventricular mass or wall thickness. There was no difference in diastolic function between patients with active acromegaly and those with treated acromegaly. Hypertensive acromegalic patients had worse diastolic function than hypertensive controls, suggesting that hypertension may further impair the left ventricular diastolic abnormality in acromegaly.

This is the first study to find evidence of subclinical cardiac diastolic dysfunction in acromegaly and it supports the suggestion that there is a specific disease of heart muscle in acromegaly.

While systemic hypertension, atherosclerosis, and diabetes mellitus may contribute to cardiovascular complications in acromegaly, cardiac failure has occurred in patients with acromegaly in the absence of these and other established causes of heart muscle disease. $^{1-5}$ Such cases suggest the existence of a specific disease of heart muscle in acromegaly. Postmortem studies showed an "abnormal myocardium" in $59 \%$ of cases of acromegaly and "definite myocarditis" in $26 \%$, suggesting that cardiac dysfunction may be more common than clinical examination alone suggests. Although Jonas et al found abnormal systolic time intervals in six of 10 patients with

Requests for reprints to Dr Edward B Raftery, Cardiology Department, Northwick Park Hospital, Watford Road, Harrow, Middlesex HA1 3UJ.

Accepted for publication 7 March 1989 acromegaly, ${ }^{7}$ more recent studies with radionuclide angiography showed no abnormality of left ventricular systolic function unless other cardiac disease was present. ${ }^{89}$

There is mounting evidence that radionuclide measurements of diastolic function are more sensitive than measurements of ejection fraction, not only in the detection and therapeutic assessment of coronary heart disease $\mathrm{e}^{10-12}$ but also in patients with left ventricular hypertrophy, which produces abnormal relaxation of the ventricle. ${ }^{13-15}$ These noninvasive measurements of diastolic function correlate well with measurements obtained invasively at cardiac catheterisation. ${ }^{16}$

We used non-invasive methods to look for evidence of a specific disease of cardiac muscle in patients with acromegaly in whom other recognised causes had been excluded. 


\section{Patients and methods}

\section{PATIENTS}

We studied 34 consecutive patients with a firm diagnosis of acromegaly. The diagnosis was based on clinical features and a resting, fasting serum concentration of growth hormone of $>10 \mathrm{mU} / 1$ which was not suppressed by a $50 \mathrm{~g}$ oral glucose load. Table 1 summarises the clinical characteristics of the patients. None of the patients had symptomatic ischaemic heart disease or evidence of heart failure at the time of study.

\section{CONTROLS}

Control data were obtained from 22 healthy volunteers with no history of cardiorespiratory disease. They were normotensive and had a normal physical examination, a normal resting electrocardiogram, and a negative maximal graded treadmill exercise test. We compared radionuclide angiographic data from the age matched controls at rest and during exercise with the data from the patients with acromegaly.
Rodrigues, Caruana, Lahiri, Nabarro, Jacobs, Raftery ESSENTIAL HYPERTENSION We compared 14 age matched patients with essential hypertension with the hypertensive acromegalic patients. These 14 patients were symptom free, had normal electrocardiograms at rest and on exercise, normal wall motion on radionuclide angiography, and were on no medication at the time of the study.

CLINICAL ASSESSMENT

We took a detailed history from each patient before physical examination for clinical evidence of $\underset{\sigma}{\omega}$ ischaemic heart disease, thyroid disease, excess alcohol consumption, and concomitant illness. Drug medication and the duration of acromegaly were recorded. Blood pressure was measured twice with the patients lying and standing and after five minutes of supine rest. Patients whose blood pressure was $>160 / 95 \mathrm{~mm} \mathrm{Hg}$ when they were lying down were considered to have hypertension. Patients with a history of hypertension who were on antihypertensive treatment were regarded as having hypertension, even if blood pressure readings at the time of the clinical assessment were $<160 / 95 \mathrm{~mm} \mathrm{Hg}$.

Table 1 Clinical details of patients with acromegaly

\begin{tabular}{|c|c|c|c|c|c|c|}
\hline Patient No & Age/sex & Hypertension & $E C G$ & $\begin{array}{l}\text { Time since } \\
\text { treatment (yr) }\end{array}$ & $\begin{array}{l}\text { Type of } \\
\text { treatment }\end{array}$ & $\begin{array}{l}\text { Growth } \\
\text { hormone } \\
\text { concentration }(m U / l)\end{array}$ \\
\hline $\begin{array}{r}1 \\
2 \\
3 \\
4 \\
5 \\
6 \\
7 \\
8 \\
9 \\
10 \\
11 \\
12 \\
13 \\
14 \\
15 \\
16 \\
17 \\
18 \\
19 \\
20 \\
21 \\
22 \\
23 \\
24 \\
25 \\
26 \\
27 \\
28 \\
29 \\
30 \\
31 \\
32 \\
33 \\
34\end{array}$ & $\begin{array}{l}56 \mathrm{~F} \\
48 \mathrm{M} \\
51 \mathrm{M} \\
62 \mathrm{M} \\
63 \mathrm{~F} \\
59 \mathrm{M} \\
52 \mathrm{M} \\
61 \mathrm{M} \\
37 \mathrm{M} \\
53 \mathrm{M} \\
64 \mathrm{~F} \\
65 \mathrm{~F} \\
49 \mathrm{M} \\
35 \mathrm{~F} \\
54 \mathrm{M} \\
66 \mathrm{~F} \\
62 \mathrm{M} \\
58 \mathrm{M} \\
41 \mathrm{~F} \\
60 \mathrm{~F} \\
56 \mathrm{M} \\
65 \mathrm{M} \\
64 \mathrm{~F} \\
42 \mathrm{M} \\
68 \mathrm{M} \\
58 \mathrm{~F} \\
28 \mathrm{M} \\
50 \mathrm{~F} \\
65 \mathrm{M} \\
70 \mathrm{~F} \\
46 \mathrm{M} \\
72 \mathrm{M} \\
53 \mathrm{M} \\
64 \mathrm{~F}\end{array}$ & $\begin{array}{l}\bar{t} \\
- \\
- \\
+ \\
- \\
- \\
- \\
+ \\
- \\
- \\
- \\
- \\
- \\
- \\
- \\
+ \\
\bar{t} \\
- \\
- \\
+ \\
- \\
+ \\
- \\
+ \\
- \\
+\end{array}$ & $\begin{array}{l}\mathbf{N} \\
\mathbf{N} \\
\mathbf{N} \\
\mathbf{N} \\
\mathbf{N} \\
\mathbf{R B B B} \\
\mathbf{N} \\
\mathbf{L B B B} \\
\mathbf{N} \\
\mathbf{L V H} \\
\mathbf{N} \\
\mathbf{N} \\
\mathbf{N} \\
\mathbf{N} \\
\mathbf{N} \\
\mathbf{N} \\
\mathbf{N} \\
\mathbf{N} \\
\mathbf{N} \\
\mathbf{N} \\
\mathbf{N} \\
\mathbf{R B B B} \\
\mathbf{N} \\
\mathbf{N} \\
\mathbf{L B B B} \\
\mathbf{N} \\
\mathbf{L V H} \\
\mathbf{N} \\
\mathbf{N} \\
\mathbf{L V H} \\
\mathbf{N} \\
\mathbf{N} \\
\mathbf{N} \\
\mathbf{N}\end{array}$ & $\begin{array}{c}6 \\
4 \\
9 \\
12 \\
4 \\
8 \\
5 \\
6 \\
9 \\
8 \\
5 \\
8 \\
8 \\
7 \\
11 \\
12 \\
9 \\
10 \\
12 \\
5 \\
4 \\
6 \\
10 \\
5 \\
10 \\
5 \\
5 \\
\text { Pre-op } \\
6 \\
\text { Pre-op } \\
\text { Pre-op } \\
7 \\
14 \\
12\end{array}$ & $\begin{array}{l}\text { HYP } \\
\text { HYP, DXT } \\
\text { HYP } \\
\text { HYP } \\
\text { B } \\
\text { HYP, B } \\
\text { HYP } \\
\text { B } \\
\text { HYP } \\
\text { HYP } \\
\text { HYP } \\
\text { HYP } \\
\text { HYP } \\
\text { HYP, B } \\
\text { HYP } \\
\text { B } \\
\text { HYP } \\
\text { HYP } \\
\text { HYP, DXT } \\
\text { HYP } \\
\text { HYP } \\
\text { B } \\
\text { HYP } \\
\text { HYP } \\
\text { DXT } \\
\text { HYP } \\
\text { HYP } \\
\text { B } \\
\text { DXT, HYP } \\
\text { - } \\
\text { Nil } \\
\text { HYP } \\
\text { HYP, B }\end{array}$ & $\begin{array}{r}1.7 \\
10.6 \\
1.9 \\
<1.9 \\
6.4 \\
<1.0 \\
1.1 \\
2.7 \\
2.3 \\
<1.0 \\
8.3 \\
5.9 \\
<1.0 \\
3.2 \\
1.6 \\
8.6 \\
<1.0 \\
1.7 \\
4.3 \\
<1.0 \\
4.6 \\
4.0 \\
4.7 \\
<1.0 \\
12.1 \\
14.0 \\
37.0 \\
39.0 \\
18.7 \\
40.2 \\
41.1 \\
70.5 \\
22.4 \\
15.8\end{array}$ \\
\hline
\end{tabular}

B, bromocriptine; DXT, radiotherapy; HYP, hypophysectomy; N, normal; LBBB, left bundle branch block; RBBB, right bundle branch $\Phi$ block; LVH, left ventricular hypertrophy. 
Blood was withdrawn for the measurement of serum concentration of growth hormone, thyroid function tests, serum creatine kinase concentration, random blood glucose, and for liver function tests, including $\gamma$-glutamyl transpeptidase.

\section{ELECTROCARDIOGRAPHY}

A standard 12 lead electrocardiogram was performed on each patient and evidence of old myocardial infarction, left ventricular hypertrophy, or conduction abnormalities was sought. Patients then underwent a maximal, symptom limited, graded treadmill exercise test with a modified Chung protocol; the bipolar electrocardiographic leads CM5 and CC5 were monitored during the test. ${ }^{17}$ Horizontal or downsloping ST segment depression of $>1 \mathrm{~mm}$ at $80 \mathrm{~ms}$ from the $\mathrm{J}$ point was regarded as evidence of ischaemia.

\section{AMBULATORY ELECTROCARDIOGRAPHIC MONITORING}

Twenty four hour electrocardiographic monitoring (Oxford Medilog) was performed to detect rhythm disturbances and the tapes were analysed with a Reynolds Medical Pathfinder and visual supervision.

\section{SYSTOLIC TIME INTERVALS}

We measured systolic time intervals on a multichannel Cambridge recorder at a paper speed of $100 \mathrm{~mm} / \mathrm{s}$ from simultaneous recordings of the electrocardiogram, carotid pulse tracing, and phonocardiogram. We recorded high frequency phonocardiograms with a piezoelectric microphone positioned on the precordium to display optimally the aortic component of the second heart sound. Carotid pulse tracings were obtained with a hand held funnel pick up that was air coupled to a crystal transducer. The electrocardiographic lead showing the earliest onset of the QRS complex was used for measurements. A mean of three values for pre-ejection period, left ventricular ejection time, and hence the ratio were derived according to the method described by Weissler and Garrand. ${ }^{18}$

\section{THALLIUM-201 SCINTIGRAPHY}

At symptom limited peak exercise a bolus of $74 \mathrm{MBq}$ thallium-201 was injected through an indwelling forearm venous cannula and exercise was continued for a further minute. Scintigrams were obtained in the anterior, left anterior oblique, and lateral views and scanning was repeated $4-6$ hours later with a cardiac gamma camera (Elscint 215M) equipped with a low energy, all-purpose collimator with an energy window of $20 \%$ around the $80 \mathrm{keV}$ photopeak of thallium-201. The scintigrams were reported "blind" by two trained observers without knowledge of the patient's clinical or laboratory findings. After subtraction for background a region of interest was placed around the left ventricle and a semiquantitative program was used to obtain counts from five different segments of the left ventricle. Segmental perfusion abnormalities were classified as fixed or reversible according to previously established criteria. ${ }^{19-21}$

Ischaemic heart disease was considered to be present if any of the following was present: (a) documented myocardial infarction; (b) angina pectoris with ST/T wave abnormalities on a resting 12 lead electrocardiogram; (c) presence of $>1 \mathrm{~mm}$ horizontal or downsloping ST segment depression $80 \mathrm{~ms}$ after the J point on exercise testing associated with the demonstration of a fixed or reversible perfusion defect on thallium-201 scintigraphy; (d) reversible perfusion defect on thallium scintigraphy even in the absence of significant ST segment depression on exercise testing.

\section{ECHOCARDIOGRAPHY}

We attempted to get a cross sectional echocardiogram in all patients with a Diasonics V-3400R real time, phased array imaging system coupled to a $2.5 \mathrm{MHz}$ transducer. Scans were obtained in the standard views in order to examine the aortic and mitral valves. We then obtained a derived $\mathbf{M}$ mode recording of the left ventricle at a paper speed of $25 \mathrm{~mm} / \mathrm{s}$, having adjusted the transducer to obtain optimal recordings of both the interventricular septum and left ventricular posterior wall. The $M$ mode scan at the level of the chordae tendineae was used to measure left ventricular end diastolic and end systolic dimensions, and the thickness of the interventricular septal wall and left ventricular posterior wall. Mean values from three cardiac cycles were used for calculation. From these values we calculated left ventricular mass using the formula of Devereux and Reichek.22

Analysis of the echocardiograms was carried out without knowledge of the clinical or laboratory findings.

\section{RADIONUCLIDE VENTRICULOGRAPHY}

Equilibrium radionuclide ventriculography was performed at rest with individuals in the supine position, after in vivo labelling of red blood cells with stannous pyrophosphate (Pyrolite) and $740 \mathrm{MBq}$ of technetium- $99 \mathrm{~m}$. Imaging was performed with a mobile gamma camera (Elscint Model 215M) in the left anterior oblique (best septal) projection. Electrocardiographic gating was used to collect and organise the data into a series of 32 frames for each cardiac cycle in order to obtain a high resolution left ventricular time-activity curve. 
Cardiac cycles falling outside a pre-selected range of acceptable cycle lengths were automatically excluded from analysis by setting an $R R$ triggering tolerance of $5 \%$; this prevented distortion of the time-activity curve by variation in cycle length. By excluding long or short cycles, the portion of the time-activity curve describing diastolic events was accurately preserved. Five million counts were collected and the data were stored in a $64 \times 64$ matrix on a dedicated computer. After nine point smoothing and time correction, left ventricular regions of interest were drawn by a computer derived counts based method. A second derivative edge defining algorithm based on a Fourier and amplitude model was used to identify the left ventricular contour in each of the 32 frames. ${ }^{23}$ After background subtraction a high resolution time-activity curve was differentiated and from the curve the point of peak filling rate was identified. Exercise radionuclide studies were performed in supine patients and volunteers using methods described in detail elsewhere. ${ }^{24-26}$

Global left ventricular systolic function was assessed by the ejection fraction, ejection rate, and ejection time. Peak filling rate, time to peak filling rate, early filling rate, and first one third filling fraction were used to describe left ventricular diastolic function. ${ }^{11} 121424-26$

Each investigation was reported blindly by trained observers without knowledge of the patient's clinical or laboratory findings or the results of the other tests.

The study was approved by the hospital ethics committee and patients and volunteers gave written informed consent before participating. We used two tailed unpaired Student's $t$ tests and linear regression analysis for statistical analysis.

\section{Results}

We studied 34 patients ( 21 men and 13 women, mean age 56 years (range 28-72)) with past or present acromegaly. In seven plasma concentrations of growth hormone were raised at the time of study. Other pituitary function was normal at the time of study; however, seven were receiving steroid replacement and three thyroxine replacement therapy. Liver function tests were normal in all patients. None had evidence of diabetes mellitus. Table 1 summarises the cardiovascular state of the patients. Hypertension was present in nine $(26 \%)$, none had electrocardiographic evidence of old myocardial infarction, and in only three $(9 \%)$ were Romhilt and Estes's electrocardiographic criteria ${ }^{27}$ for left ventricular hypertrophy fulfilled. All patients were in sinus rhythm at the time of study. There were conduction abnormalities on the resting electrocardiogram in four (12\%). A total of $14 \mathrm{had}$ evidence of hypertension or ischaemic heart disease or both. One $\stackrel{C}{.}$ patient (case 23) who had an inconclusive exercise $\overrightarrow{\vec{F}} \cdot$ test and who did not undergo thallium scintigraphy $\overrightarrow{0}$ or a wall motion study was excluded from analysis.

\section{EXERCISE TESTING}

Only one patient stopped exercising because of anginal pain. Fatigue was the end point in 17 and $s$ breathlessness in 15. Five achieved the target heart $\vec{O}$ rate and stopped because of fatigue. Five had positive $\overrightarrow{-}$ ST segment criteria for ischaemia but all of these had $\omega_{\sigma}$ normal exercise and redistribution thallium-201 scans and normal wall motion on radionuclide ventriculography.

\section{AMBULATORY ELECTROCARDIOGRAPHIC} MONITORING

Arrhythmias were detected in 14 patients. The most common finding was asymptomatic isolated ven- $\mathcal{D}$ tricular extrasystoles. One of these patients (case 27) $\frac{\mathbb{D}}{\stackrel{D}{~}}$ had prolonged asymptomatic episodes of ventricular $\frac{\mathbb{}}{3}$ bigeminy. In another patient runs of ventricular tachycardia were recorded, which were producing symptoms of palpitation and dizziness (case 8). This $\vec{\oplus}$ patient had left bundle branch block on the resting electrocardiogram, abnormal wall motion on radionuclide ventriculography, and a reversible perfusion defect on thallium scintigraphy; it was therefore deduced that he had ischaemic heart disease. Two

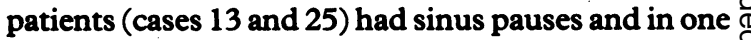
of these (case 13) asymptomatic pauses of up to 4.4 seconds were recorded at night.

\section{SYSTOLIC TIME INTERVALS}

According to the normal range $(0.25-0.41)$ defined by Martins et $\mathrm{al}^{8}$ systolic time intervals were abnormal at rest in only three $(9 \%)$; all had other evidence of ischaemic heart disease with dilated left ventricles. Systolic time intervals were only abnormal when there were other recognisable cardiac abnormalities.

THALLIUM-201 SCINTIGRAPHY

Exercise and redistribution thallium-201 imaging $D$ was performed in 28 patients. There were fixed perfusion defects suggestive of myocardial scarring $N$ in four and reversible perfusion abnormalities were present in a further four patients (table 2).

\section{ECHOCARDIOGRAPHY}

Cross sectional and $M$ mode echocardiography was attempted in all patients, but adequate scans for $\mathbb{E}$ calculation of left ventricular mass could be obtained ${ }^{+}$ in only 25 . In the remaining nine patients only qualitative assessment of the echocardiograms was $\underset{\mathbb{D}}{\vec{D}}$ possible. Valve abnormality was detected in only one $\frac{\rho}{\mathbb{D}}$ patient (case 12), whose echocardiogram indicated 
the presence of a thickened, sclerotic aortic valve with mild stenosis. Left ventricular hypertrophy (wall thickness $>11 \mathrm{~mm}$ ) was detected in $12(48 \%)$. In one patient (case 30) concentric left ventricular hypertrophy was associated with systolic anterior motion of the anterior mitral leaflet and calcification of the posterior mitral annulus but there were no other features to suggest hypertrophic cardiomyopathy. In another patient there was early systolic closure of the aortic valve (case 34 ).

There was no significant correlation between left ventricular wall thickness and peak filling rate $(r=$ $0 \cdot 1, p=$ NS for septal thickness; and $r=0 \cdot 3, p=N S$ for posterior free wall thickness). The left ventricular cavity was dilated in five patients and of these two had other evidence of ischaemic heart disease. The remaining three had no evidence of hypertension or ischaemic heart disease. Increased left ventricular mass was detected in $17(68 \%)$ of the patients by the criteria ( $>200 \mathrm{~g}$ ) of Mather et al. ${ }^{28}$ No significant correlation was detected between the left ventricular mass and peak filling rate $(r=-0 \cdot 3, p=N S)$.
RADIONUCLIDE VENTRICULOGRAPHY

Nineteen patients had no recognisable cause of heart disease. None was receiving any cardioactive medication at the time of study. The results of radionuclide ventriculography in these patients were analysed in detail and compared with the results from 22 age matched controls (table 3). None of these patients developed abnormalities of regional wall motion on exercise. Resting systolic function was similar in both the controls and the patients, but peak filling rates at rest were significantly depressed in the patients $(p<$ 0.005 ) despite comparable resting heart rates (fig 1 ). Mean exercise ejection fraction and ejection rate in the two groups were similar, but ejection time and time to peak filling rate were longer in the patients ( $p<0.05$ and $p<0.02$ respectively). The significantly higher exercise heart rate in the controls than the patients $(p<0.01)$ could account for this result. The diastolic indices remained abnormal on exercise in the patients. The change in mean ejection fraction on exercise was $+4 \cdot 1(8 \cdot 4) \%$ in the control group and $+2 \cdot 7(10 \cdot 0) \%$ in the patients $(p=N S)$.

Table 2 Results of exercise testing, echocardiography, thallium scintigraphy, and nuclear angiography

\begin{tabular}{|c|c|c|c|c|c|c|}
\hline Patient No & $\begin{array}{l}\text { Exercise } \\
\text { time (min) }\end{array}$ & $G X T$ result & $G X T$ symptoms & Thallium scan & $R N A W M A$ & $L V$ mass $(g)$ \\
\hline $\begin{array}{l}1 \\
2 \\
3 \\
4 \\
5 \\
6 \\
7 \\
8 \\
9 \\
10 \\
11 \\
12 \\
13 \\
14 \\
15 \\
16 \\
17 \\
18 \\
19 \\
20 \\
21 \\
22 \\
23 \\
24 \\
25 \\
26 \\
27 \\
28 \\
29 \\
30 \\
31 \\
32 \\
33 \\
34\end{array}$ & 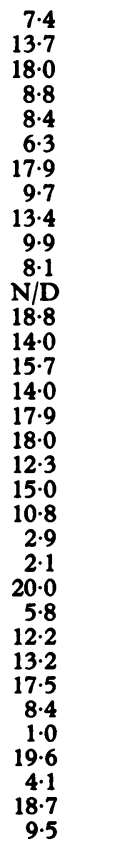 & $\begin{array}{l}- \\
+ \\
+ \\
- \\
- \\
- \\
I / C \\
- \\
+ \\
\text { N/D } \\
- \\
- \\
+ \\
- \\
- \\
- \\
- \\
- \\
I / C \\
I \\
I / C \\
- \\
- \\
I \\
I / C\end{array}$ & $\begin{array}{l}\text { SOB } \\
\text { SOB } \\
\text { F } \\
\text { THR/F } \\
\text { SOB } \\
\text { SOB } \\
\text { THR/F } \\
\text { SOB/VE } \\
\text { THR/F } \\
\text { SOB } \\
\text { F } \\
\text { N/D } \\
\text { THR/F } \\
\text { F } \\
\text { F } \\
\text { SOB } \\
\text { F } \\
\text { F } \\
\text { SOB } \\
\text { F } \\
\text { F } \\
\text { SOB } \\
\text { SOB } \\
\text { THR/F } \\
\text { F } \\
\text { F } \\
\text { SOB } \\
\text { SOB } \\
\text { AP } \\
\text { SOB } \\
\text { F } \\
\text { SOB } \\
\text { F } \\
\text { SOB }\end{array}$ & $\begin{array}{l}\mathbf{N} \\
\mathbf{N} \\
\mathbf{N} \\
\mathbf{N} \\
\mathbf{N} \\
\mathbf{N} \\
\mathbf{N} / \mathbf{D} \\
\mathbf{R} \\
\mathbf{R} \\
\mathbf{N} \\
\mathbf{N} \\
\mathbf{N} \\
\mathbf{N} \\
\mathbf{N} / \mathbf{D} \\
\mathbf{N} \\
\mathbf{N} \\
\mathbf{N} \\
\mathbf{N} \\
\mathbf{N} \\
\mathbf{N} / \mathbf{D} \\
\mathbf{N} \\
\mathbf{F x} \\
\mathbf{N} / \mathbf{D} \\
\mathbf{N} / \mathbf{D} \\
\mathbf{F X} \\
\mathbf{N} \\
\mathbf{N} \\
\mathbf{N} / \mathbf{D} \\
\mathbf{R} \\
\mathbf{R} \\
\mathbf{F x} \\
\mathbf{F x} \\
\mathbf{N} \\
\mathbf{N}\end{array}$ & $\begin{array}{l}0 \\
0 \\
0 \\
0 \\
0 \\
0 \\
\text { N/D } \\
+ \\
0 \\
0 \\
0 \\
0 \\
0 \\
\text { N/D } \\
0 \\
0 \\
0 \\
0 \\
0 \\
0 \\
0 \\
+ \\
\text { N/D } \\
0 \\
+ \\
0 \\
0 \\
0 \\
+ \\
0 \\
0 \\
0 \\
0 \\
0\end{array}$ & $\begin{array}{l}155 \\
227 \\
199 \\
291 \\
243 \\
214 \\
185 \\
- \\
- \\
193 \\
- \\
139 \\
- \\
228 \\
333 \\
207 \\
258 \\
287 \\
261 \\
261 \\
- \\
- \\
- \\
232 \\
591 \\
167 \\
249 \\
229 \\
- \\
186 \\
353 \\
361 \\
160 \\
-\end{array}$ \\
\hline
\end{tabular}

WMA, wall motion abnormality; THR, target heart rate; SOB, shortness of breath; F, fatigue; I/C, inconclusive; $R$, reversible defect; Fx, fixed defect; N/D, not done; GXT, graded treadmill exercise test; AP, angina pectoris; N, normal angiography; VE, ventricular extrasystoles; RNA, radionuclide angiography. 
190

\section{RADIONUCLIDE VENTRICULOGRAPHY IN}

HYPERTENSIVE ACROMEGALIC PATIENTS

The results of radionuclide ventriculography in the nine hypertensive acromegalic patients were compared with those in normal age matched normotensive controls and with 14 age matched patients with essential hypertension (table 4). Five of the hypertensive acromegalic patients were receiving $\beta$ block-

Table 3 Results (mean (SD)) of radionuclide angiography in the 19 normotensive acromegalic patients and the 22 age matched controls

\begin{tabular}{|c|c|c|c|}
\hline & Controls & $\begin{array}{l}\text { Normotensive } \\
\text { and } \\
\text { aromegalic }\end{array}$ & $\begin{array}{l}\text { Controls } v \\
\text { acromegalics }\end{array}$ \\
\hline $\begin{array}{l}\text { Rest variables: } \\
\text { Ejection fraction (\%) } \\
\text { Ejection rate (EDV/s) } \\
\text { Ejection time (ms) } \\
\text { Peak filling rate (EDV/s) } \\
\text { Early filling rate (EDV/s) }\end{array}$ & $\begin{array}{c}61(7) \\
1.8(0.3) \\
350(41) \\
\quad 2.9(0.4) \\
8) \quad 1.3(0.4)\end{array}$ & $\begin{array}{c}61(10) \\
2 \cdot 0(0 \cdot 5) \\
330(57) \\
2 \cdot 4(0.7) \\
1 \cdot 1(0.5)\end{array}$ & $\begin{array}{l}\text { NS } \\
\text { NS } \\
\text { NS } \\
<0.005 \\
\text { NS }\end{array}$ \\
\hline $\begin{array}{l}\text { Time to peak filling rate } \\
\text { (ms) } \\
\text { First one third filling } \\
\text { fraction } \\
\text { Heart rate (bpm) }\end{array}$ & $\begin{array}{l}161(56) \\
0 \cdot 5(0 \cdot 2) \\
69(10)\end{array}$ & $\begin{array}{l}193(67) \\
0 \cdot 4(0 \cdot 2) \\
72(9)\end{array}$ & $\begin{array}{l}\text { NS } \\
\text { NS } \\
\text { NS }\end{array}$ \\
\hline $\begin{array}{l}\text { Exercise variables: } \\
\text { Ejection fraction (\%) } \\
\text { Ejection rate (EDV/s) } \\
\text { Ejection time (ms) } \\
\text { Peak filling rate (EDV/s) } \\
\text { Early filling rate (EDV/s) }\end{array}$ & $\begin{array}{c}64(9) \\
2 \cdot 8(0 \cdot 7) \\
230(46) \\
5 \cdot 7(1 \cdot 2) \\
2 \cdot 7(0 \cdot 9)\end{array}$ & $\begin{array}{c}63(9) \\
2 \cdot 4(0 \cdot 4) \\
260(30) \\
4 \cdot 9(1 \cdot 7) \\
2 \cdot 5(1 \cdot 1)\end{array}$ & $\begin{array}{l}\text { NS } \\
\text { NS } \\
<0.05 \\
\text { NS } \\
\text { NS }\end{array}$ \\
\hline $\begin{array}{l}\text { Time to peak filling rate } \\
\text { (ms) }\end{array}$ & $121(32)$ & $155(53)$ & $<0.02$ \\
\hline $\begin{array}{l}\text { First one third filling } \\
\text { fraction } \\
\text { Heart rate (bpm) }\end{array}$ & $\begin{array}{l}0 \cdot 4(0 \cdot 2) \\
140(24)\end{array}$ & $\begin{aligned} & 0 \cdot 3(0 \cdot 1) \\
& 121(16)\end{aligned}$ & $\begin{array}{l}\text { NS } \\
<0.01\end{array}$ \\
\hline
\end{tabular}

EDV, end diastolic volume.
Rodrigues, Caruana, Lahiri, Nabarro, Jacobs, Raftery ers and one was on calcium antagonists at the time of study.

Resting ejection fraction was similar in the three groups, as were resting ejection rate and ejection time. Mean (SD) resting peak filling rate in the normal subjects was $2.9(0.4) \mathrm{EDV} / \mathrm{s}$. The essential

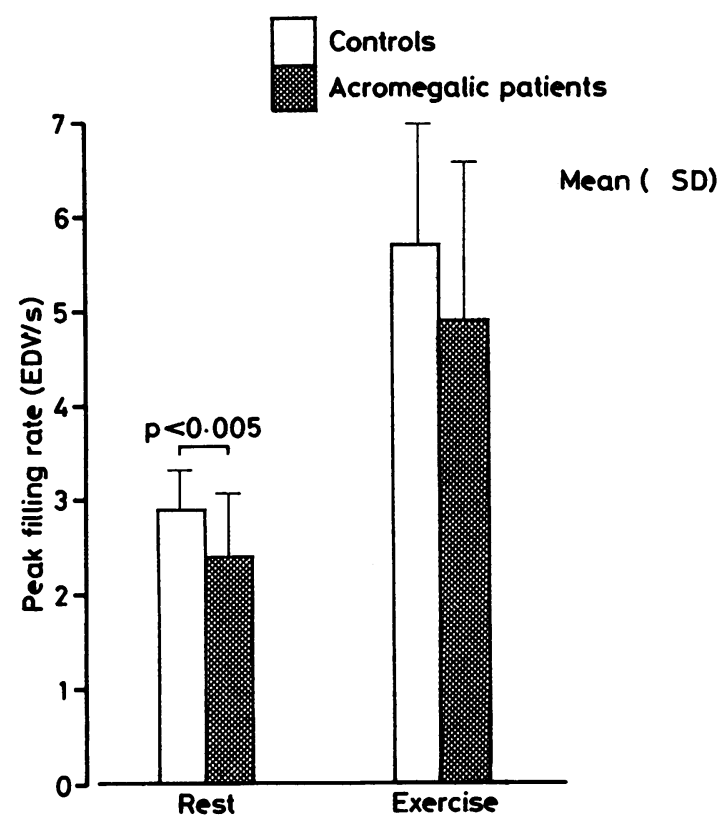

Fig 1 Peak filling rate at rest and on exercise in normotensive patients with acromegaly and in age matched controls. EDV, end diastolic volumes."

Table 4 Results (mean (SD)) of radionuclide angiography in hypertensive acromegalic patients, patients with essential hypertension, and age-matched controls

\begin{tabular}{|c|c|c|c|c|c|c|c|c|c|}
\hline \multirow[b]{2}{*}{$\begin{array}{l}\text { Rest variables: } \\
\text { Ejection fraction (\%) } \\
\text { Ejection rate (EDV/s) } \\
\text { Ejection time (ms) } \\
\text { Peak filling rate (EDV/s) } \\
\text { Early filling rate (EDV/s) } \\
\text { Time to peak filling rate (ms) } \\
\text { First one third filling fraction } \\
\text { Heart rate (bpm) } \\
\text { Systolic blood pressure (mm Hg) } \\
\text { Diastolic blood pressure (mm Hg) } \\
\text { Age (yr) }\end{array}$} & \multicolumn{2}{|c|}{$\begin{array}{l}\text { Controls } \\
(n=14)\end{array}$} & \multicolumn{2}{|c|}{$\begin{array}{l}E H T \\
(n=14)\end{array}$} & \multicolumn{2}{|c|}{$\begin{array}{l}A H T \\
(n=9)\end{array}$} & \multirow[b]{2}{*}{$\begin{array}{l}C v E H T \\
\\
\text { NS } \\
\text { NS } \\
\text { NS } \\
\text { NS } \\
<0.001 \\
\text { NS } \\
<0.05 \\
<0.05 \\
\text { NS } \\
<0.001 \\
\text { NS }\end{array}$} & \multirow[b]{2}{*}{$\begin{array}{l}C v A H T \\
\text { NS } \\
\text { NS } \\
\text { NS } \\
<0 \cdot 001 \\
<0 \cdot 02 \\
<0 \cdot 01 \\
\text { NS } \\
\text { NS } \\
\text { NS } \\
\text { NS } \\
\text { NS }\end{array}$} & \multirow{2}{*}{$\begin{array}{l}E H T v A H T \\
\text { NS } \\
\text { NS } \\
\text { NS } \\
<0.01 \\
<0.001 \\
<0.05 \\
\text { NS } \\
<0.01 \\
\text { NS } \\
\text { NS } \\
\text { NS }\end{array}$} \\
\hline & $\begin{array}{c}60 \\
1 \cdot 8 \\
343 \\
2 \cdot 9 \\
1 \cdot 4 \\
152 \\
0 \cdot 46 \\
70 \\
138 \\
85 \\
54\end{array}$ & $\begin{array}{c}(6) \\
(0.3) \\
(46) \\
(0.4) \\
(0.5) \\
(53) \\
(0.25) \\
(11) \\
(16) \\
(10) \\
(8)\end{array}$ & $\begin{array}{c}57 \\
1 \cdot 9 \\
337 \\
2 \cdot 7 \\
0 \cdot 2 \\
168 \\
0 \cdot 28 \\
82 \\
155 \\
102 \\
52\end{array}$ & $\begin{array}{l}(8) \\
(0 \cdot 3) \\
(54) \\
(0 \cdot 8) \\
(0 \cdot 2) \\
(41) \\
(0 \cdot 17) \\
(16) \\
(21) \\
(4) \\
(8)\end{array}$ & $\begin{array}{c}63 \\
2 \cdot 0 \\
350 \\
1 \cdot 8 \\
0 \cdot 9 \\
237 \\
0 \cdot 33 \\
62 \\
155 \\
94 \\
56\end{array}$ & $\begin{array}{l}(9) \\
(0.6) \\
(77) \\
(0.5) \\
(0.4) \\
(87) \\
(0.17) \\
(12) \\
(25) \\
(10) \\
(15)\end{array}$ & & & \\
\hline $\begin{array}{l}\text { Exercise variables: } \\
\text { Ejection fraction (\%) } \\
\text { Ejection rate (EDV/s) } \\
\text { Ejection time (ms) } \\
\text { Peak filling rate (EDV/s) } \\
\text { Early filling rate (EDV/s) } \\
\text { Time to peak filling rate (ms) } \\
\text { First one third filling fraction } \\
\text { Heart rate (bpm) }\end{array}$ & $\begin{array}{c}64 \\
2 \cdot 6 \\
246 \\
5 \cdot 3 \\
2 \cdot 6 \\
124 \\
0 \cdot 41 \\
131\end{array}$ & $\begin{array}{l}(9) \\
(0 \cdot 5) \\
(43) \\
(1 \cdot 3) \\
(0 \cdot 9) \\
(34) \\
(0 \cdot 16) \\
(21)\end{array}$ & $\begin{array}{c}63 \\
2 \cdot 7 \\
234 \\
5 \cdot 0 \\
2 \cdot 2 \\
114 \\
0 \cdot 44 \\
129\end{array}$ & $\begin{array}{l}(8) \\
(0 \cdot 7) \\
(40) \\
(1 \cdot 1) \\
(1 \cdot 2) \\
(34) \\
(0 \cdot 23) \\
(19)\end{array}$ & $\begin{array}{c}58 \\
2 \cdot 0 \\
290 \\
3 \cdot 3 \\
1 \cdot 4 \\
203 \\
0 \cdot 2 \\
98\end{array}$ & $\begin{array}{l}(14) \\
(0 \cdot 5) \\
(80) \\
(1 \cdot 0) \\
(0 \cdot 7) \\
(59) \\
(0 \cdot 12) \\
(19)\end{array}$ & $\begin{array}{l}\text { NS } \\
\text { NS } \\
\text { NS } \\
\text { NS } \\
\text { NS } \\
\text { NS } \\
\text { NS } \\
\text { NS }\end{array}$ & $\begin{array}{l}\text { NS } \\
<0.05 \\
\text { NS } \\
<0.005 \\
<0.01 \\
<0.002 \\
<0.001 \\
<0.005\end{array}$ & $\begin{array}{l}\text { NS } \\
<0.05 \\
<0.05 \\
<0.005 \\
\text { NS } \\
<0.001 \\
<0.02 \\
<0.005\end{array}$ \\
\hline
\end{tabular}

EHT, essential hypertensives; AHT, hypertensive acromegalic patients; C, controls; EDV, end diastolic volume. 

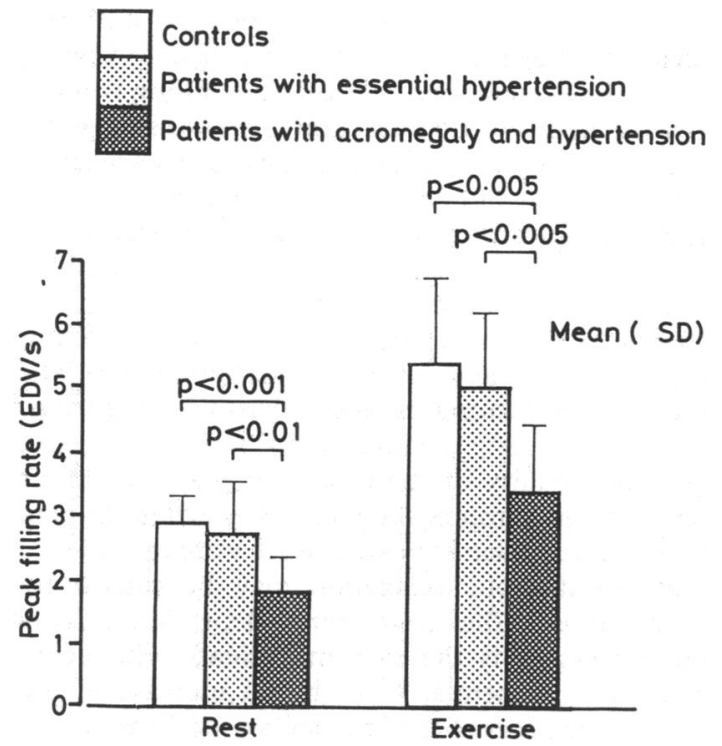

Fig 2 Peak filling rate at rest and on exercise in hypertensive patients with acromegaly and in age-matched controls and patients with essential hypertension. EDV, end diastolic volumes.

hypertension group had a slightly lower peak filling rate $(2 \cdot 7(0.8) \mathrm{EDV} / \mathrm{s}, \mathrm{p}=\mathrm{NS})$ but in the hypertensive acromegalic patients the peak filling rate was significantly depressed $(1.8(0.5) \mathrm{EDV} / \mathrm{s}, \mathrm{p}<0.001)$ (fig 2). A similar abnormality was seen in time to peak filling rate. The first one third filling fraction was abnormal in the patients with essential hypertension but not in those with acromegaly and hypertension. The early filling rate was lower in both hypertensive groups than in the controls.

\section{COMPARISON BETWEEN ACTIVE AND TREATED ACROMEGALY}

Of the acromegalic patients studied, seven had raised ( $>10 \mathrm{mU} / \mathrm{l}$ ) serum concentrations of growth hormone at the time of study. The results of radionuclide ventriculography in this group were compared with results from 13 patients whose growth hormone concentrations were well within the normal range $(<10 \mathrm{mU} / \mathrm{l})$ at the time of the study. No significant difference in either systolic or diastolic function was detected between these groups although resting peak filling rate was slightly lower in patients with active disease $(2.0(0.9) \mathrm{EDV} / \mathrm{s})$ than in treated patients $(2 \cdot 2(0 \cdot 8) \mathrm{EDV} / \mathrm{s}) \mathrm{p}=\mathrm{NS})$.

\section{Discussion}

Cardiac hypertrophy, "cardiomyopathy", and congestive cardiac failure have been described in as many as one third of patients with acromegaly ${ }^{2-4}$ but the pathophysiology of cardiac dysfunction in this condition remains unclear. ${ }^{79}$ In this study there was evidence of hypertension in $26 \%$ of patients, which accords with other reported series, as did the frequency of ischaemic heart disease. ${ }^{62}$ Cardiac dysfunction in acromegaly has been attributed to these known causes of heart disease. ${ }^{9}$ No previous study, however, has excluded coronary artery disease and hypertension from the study population. We have attempted to do this using a combination of electrocardiography, exercise testing, and stress thallium-201 scintigraphy.

Using electrocardiography alone, we detected left ventricular hypertrophy by Romhilt and Estes's criteria ${ }^{27}$ in only three $(9 \%)$ of our patients. But electrocardiography has limitations for detecting ventricular hypertrophy in these patients, because acromegaly results in a considerable alteration in the shape of the chest wall with an increase in anteroposterior diameter and hence greater than normal electrical insulation of the heart from surface electrodes. When it is technically feasible, echocardiography overcomes these difficulties and in this study there was evidence of left ventricular hypertrophy in $48 \%$ and an increased left ventricular mass in $68 \%$. Similar results were reported by others. ${ }^{28}$

In five (15\%) the exercise test was positive by ST segment criteria but in all of them thallium-201 scintigraphy was normal. A previous study from our department showed that positive exercise tests in patients with left ventricular hypertrophy are inaccurate predictors of coronary artery disease unless thallium-201 scintigraphy is also abnormal. ${ }^{30}$ Quantitative thallium-201 imaging is well established and has been shown to be a highly sensitive technique for detecting underlying coronary artery disease. ${ }^{1931}$ Harris et al have also reported false positive exercise tests in patients with left ventricular hypertrophy and angiographically normal coronary arteries. ${ }^{32}$ Because angina or wall motion abnormalities did not develop in any of these acromegalic patients during exercise radionuclide angiography, these positive exercise test results in conjunction with negative thallium-201 scans make it unlikely that obstructive disease was present in the large coronary arteries.

Cardiovascular morbidity is more common in acromegaly. ${ }^{29}$ While cardiac failure may be responsible for this, some workers reported an increased incidence of arrhythmias in these patients. ${ }^{5}$ In our series, 14 of the 34 patients had arrhythmias. One patient had several episodes of symptomatic ventricular tachycardia, but this patient undoubtedly had ischaemic heart disease and this was probably the cause of the arrhythmia. Thirteen patients had frequent ventricular extrasystoles and in one patient 
there were long periods of asymptomatic ventricular bigeminy. Arrhythmia was also more in patients with left ventricular hypertrophy and strain in the presence of normal coronary arteries, ${ }^{33} \mathrm{a}$ finding that may also be applicable to acromegalic patients.

Others have used systolic time intervals to study patients with acromegaly, with conflicting results. Jonas et al studied 10 patients and showed an abnormally high PEP/LVET (pre-ejection phase/ left ventricular ejection time) ratio in $\mathrm{six}^{7}$-but five patients had hypertension, one had thyrotoxicosis, and one had diabetes mellitus. Furthermore, coronary heart disease was excluded by history and physical examination alone, without exercise testing or thallium-201 scintigraphy. Because it is well recognised that an increased PEP/LVET ratio may occur in patients with congestive cardiac failure, hypertension, and various myocardial diseases, the demonstration of an abnormality in this group of patients does not necessarily imply that impaired systolic function was caused by acromegaly. Martins et al studied 16 patients and found an abnormally high PEP/LVET in three with concomitant angina or hypertension.8 Only one other patient, in whom coronary artery disease and hypertension had been excluded, showed abnormal systolic time intervals. Similarly, four of the 23 patients studied by Mather et al had high PEP/LVET ratios. ${ }^{28}$ In three of these, causes other than acromegaly were clearly implicated. Our findings accord with those of Martins $e t$ $a l^{8}$ and Mather et $a l^{28}$ because an abnormal PEP/ LVET ratio was only detected in patients with coexisting coronary heart disease. Systolic time intervals, however, are not as sensitive or specific as radionuclide angiography for assessing cardiac function $^{34}$ and it is therefore unlikely that subtle subclinical cardiac dysfunction would be detected by this method.

Most workers used echocardiography for assessing left ventricular function. ${ }^{28353}$ This technique is insensitive because of the assumptions necessary to calculate ejection fraction. ${ }^{37}$ Furthermore, any errors in measuring wall thickness and cavity size are exaggerated when these values are used to derive volumes. It is now generally accepted that radionuclide angiography is a more accurate method of assessing left ventricular function. In two previous studies, patients with acromegaly were investigated by radionuclide angiography, ${ }^{89}$ and in neither was cardiac dysfunction shown unless coexisting hypertension or ischaemic heart disease was present. Only left ventricular ejection fraction (systolic function) was measured, however. Our results accord with these studies in that we were unable to detect any abnormality of systolic function in acromegalic patients who had no evidence of other cardiac disease.
Left ventricular diastolic function has not previously been studied in acromegaly. Several workers have suggested that diastolic filling is more sensitive than ejection fraction for assessing early impairment of cardiac function, not only in ischaemic heart disease ${ }^{1011}$ but also in other conditions such as hypertrophic cardiomyopathy ${ }^{15}$ and hypertension. ${ }^{14}$ In our study there was a highly significant difference in resting peak filling rate between controls and patients with acromegaly. The diastolic peak filling rate was reduced and the time to peak filling rate was prolonged, indicating impaired diastolic relaxation. Diastolic indices remained abnormal on exercise. This abnormality of diastolic filling was apparent even in those acromegalic patients in whom hypertension and ischaemic heart disease were excluded.

Altered diastolic relaxation may be caused by abnormalities in the active energy-dependent relaxation process as is the case in patients with acute myocardial ischaemia, ${ }^{10-12}$ or by an increase in the visco-elastic properties of the left ventricle as occurs after myocardial infarction. ${ }^{38}{ }^{39}$ While the increased left ventricular mass seen in acromegaly may reduce compliance, this factor is unlikely to be solely responsible for our findings, because there was no correlation between diastolic filling variables and left ventricular wall thickness or left ventricular mass. Lie and Grossman showed mononuclear cell infiltrate or myocarditis in up to $59 \%$ of cases of acromegaly. ${ }^{6}$ Hejmancik et al also reported increased interstitial fibrosis in acromegaly. ${ }^{3}$ It is not known whether the finding of an inflammatory reaction relates to the activity of the acromegaly with fibrosis representing "healing" once the condition is treated. Although we found no difference in diastolic dysfunction between active and treated acromegaly, the reduced peak filling rate detected in our study may well reflect these histological abnormalities, which would be expected to increase ventricular stiffness and reduce compliance. Our study therefore adds clinical support to the necropsy evidence for a specific heart muscle disease in acromegaly.

Furthermore, acromegalic patients with coexistent hypertension showed greater depression of diastolic function than age and blood pressure matched patients with essential hypertension, suggesting that hypertension may be less well tolerated when there are underlying acromegalic changes in the myocardium; this factor may contribute to the increased frequency of clinical cardiac disease in acromegaly. Some of the hypertensive acromegalic patients in our study, however, were receiving $\beta$ blockers and abnormalities of peak filling rate may have been exaggerated by the negative chronotropic properties of these agents. Early therapeutic intervention with addition of calcium antagonists may improve the diastolic abnormalities detected. ${ }^{15}$ 
We found evidence of subclinical cardiac dysfunction in acromegaly in the absence of other known causes of heart disease and our findings are consistent with the histological abnormalities previously shown in the hearts of patients with acromegaly.

We thank Mrs Gill Clarke and Mr David Hinge for their invaluable assistance with the technical and statistical aspects of this study and Dr R Himsworth and Dr R Clayton (Endocrinology Department, Northwick Park Hospital) for allowing us to study their patients.

\section{References}

1 Pepine CJ, Aloia J. Heart muscle disease in acromegaly. Am J Med 1970;48:530-4.

2 Courville CB, Mason VR. The heart in acromegaly. Arch Intern Med 1938;61:704-13.

3 Hejmancik MR, Bradfield JY, Hermann GR. Acromegaly and the heart; a clinical and pathologic study. Ann Intern Med 1951;34:1445-56.

4 McGuffin WL, Sherman BM, Roth J, et al. Acromegaly and cardiovascular disorders. A prospective study. Ann Intern Med 1974;81:11-8.

5 Rossi L, Thiene G, Caregaro L, Giordano R, Lauro S. Dysrhythmias and sudden death in acromegalic heart disease. A clinicopathologic study. Chest 1977;72: 495-8.

6 Lie JT, Grossman SJ. Pathology of the heart in acromegaly: anatomic findings in 27 autopsied patients. Am Heart J 1980;100:41-52.

7 Jonas EA, Aloia JF, Lane FJ. Evidence of subclinical heart muscle dysfunction in acromegaly. Chest 1975; 67:190-4.

8 Martins JB, Kerber RE, Sherman BM, Marcus ML, Ehrhardt JC. Cardiac size and function in acromegaly. Circulation 1977;56:863-9.

9 O'Keefe JC, Grant SJ, Wiseman JC, et al. Acromegaly and the heart-echocardiographic and nuclear imaging studies. Aust NZ J Med 1982;12:603-7.

10 Bonow RO, Bacharach SL, Green MV, et al. Impaired left ventricular diastolic filling in patients with coronary artery disease: assessment with radionuclide cineangiography. Circulation 1981;64:315-23.

11 Rodrigues EA, Lahiri A, Raftery EB. An objective noninvasive method for detecting early diastolic dysfunction in patients with coronary artery disease [Abstract]. Br Heart J 1986;55:511.

12 Rodrigues EA, Lahiri A, Raftery EB. Improvement in diastolic dysfunction in ischaemic heart disease after treatment with calcium antagonists [Abstract]. Clin Sci 1986;70(suppl 13):6.

13 Qureshi S, Wagner HN, Alderson PO, et al. Evaluation of left ventricular function in normal persons and patients with heart disease. J Nucl Med 1978;19: 135-41.

14 Inouye I, Massie B, Loge D, et al. Abnormal left ventricular filling; an early finding in mild to moderate hypertension. Am J Cardiol 1984;53:120-6.

15 Bonow RO, Rosing DR, Bacharach SL, et al. Effects of verapamil on left ventricular systolic function and diastolic filling in patients with hypertrophic cardiomyopathy. Circulation 1981;64:787-96.

16 Magorien DJ, Shaffer P, Bush C, et al. Haemodynamic correlates for timing intervals, ejection rate and filling rate derived from the radionuclide angiographic volume curve. Am J Cardiol 1984;53:567-71.

17 Rodrigues EA, Lahiri A, Hughes LO, Kohli RS, Whittington JR, Raftery EB. Anti-anginal efficacy of carvedilol, a beta-blocker with vasodilating activity. Am J Cardiol 1986;58:916-21.

18 Weissler AM, Garrand CL. Systolic time intervals in cardiac disease. Mod Concepts Cardiovasc Dis 1971;40:1-8.

19 O'Hara MJ, Lahiri A, Whittington JR, Crawley JCW, Raftery EB. Detection of high risk coronary artery disease by thallium imaging. $\mathrm{Br}$ Heart $J$ 1985;53: 616-23.

20 Lahiri A, Zanelli GD, O'Hara MJ, et al. Simultaneous measurement of left ventricular function and myocardial perfusion during a single exercise test: dual isotope imaging with gold-195m and thallium-201. Eur Heart J 1986;7:493-500.

21 Lahiri A, O'Hara MJ, Bowles MJ, Crawley JCW, Raftery EB. Influence of left ventricular function and severity of coronary artery disease on exercise induced pulmonary thallium-201 uptake. Int J Cardiol 1984;5:475-90.

22 Devereux RB, Reichek N. Echocardiographic determination of left ventricular mass in man: anatomic validation of the method. Circulation 1977;55:613-8.

23 Adam WE, Tarkowska A, Bitter F, Stauch M, Geffers H. Equilibrium (gated) radionuclide ventriculography. Cardiovasc Radiol 1979;2:161-73.

24 Rodrigues EA, Lahiri A, Raftery EB. Improvement in left ventricular diastolic function in patients with stable angina after chronic treatment with verapamil and nicardipine. Eur Heart $J$ 1987;8:624-9.

25 Lahiri A, Rodrigues EA, Al-Khawaja IM, Raftery EB. Effects of a new vasodilating beta-blocking drug (Carvedilol) on left ventricular function in stable angina pectoris. Am J Cardiol 1987;59:769-77.

26 Hains ADB, Al-Khawaja I, Hinge DA, Lahiri A, Raftery EB. Radionuclide left ventricular ejection fraction: a comparison of three methods. Br Heart $J$ 1987;57:242-6.

27 Romhilt DW, Estes EH. A point-score system for the ECG diagnosis of left ventricular hypertrophy. Am Heart J 1968;75:752-8.

28 Mather HM, Boyd MJ, Jenkins JS. Heart size and function in acromegaly. Br Heart $J$ 1979;41:697-701.

29 Wright AD, Hill DM, Lowy C, Fraser TR. Mortality in acromegaly. $Q J$ Med (new series) 1970;39:1-16.

30 Heber ME, Caruana MP, Brigden G, Clarke G, Lahiri A, Raftery EB. Diagnosis of chest pain in hypertensive patients [Abstract]. Clin Sci 1987;72(suppl 16):8P.

31 Lahiri A. Myocardial perfusion scintigraphy with single photon radionuclides. Current Opinion Cardiol 1986; 1:926-32.

32 Harris CN, Aronow WS, Parker DP, Kaplan MA. Treadmill stress test in left ventricular hypertrophy. Chest 1973;63:353-7.

33 McLenachan JM, Henderson E, Dargie HJ. Arrhyth- 
mias in the presence of left ventricular hypertrophy and strain and normal coronary arteries [Abstract]. Clin Sci 1986;71(suppl 15):56P.

34 Braunwald E, Rose J, Sonnenblick EH. Mechanisms of contraction of the normal and failing heart 2nd ed. Boston: Little Brown, 1976.

35 Smallridge RC, Rajfer S, Davia J, Schaaf M. Acromegaly and the heart. An echocardiographic study. Am J Med 1979;66:22-7.

36 Savage DD, Henry WL, Eastmen RC, Borer JS, Gorden P. Echocardiographic assessment of cardiac anatomy and function in acromegalic patients. $\mathrm{Am} \mathrm{J}$ Med 1979;67:823-9.
37 Feigenbaum H. Echocardiography. 2nd ed. Philadelphia: Lea and Febiger, 1979.

38 Diamond G, Forrester JS. Effect of coronary artery disease and acute myocardial infarction on left ventricular compliance in man. Circulation 1972;45:11-9.

39 Rodrigues EA, Lahiri A, Hinge DA, Raftery EB. Left ventricular diastolic function in patients with chronic $\stackrel{\mathbb{D}}{\AA}$ stable angina: comparison with normal subjects. $A m J$ \& Noninvas Cardiol 1988;244-54.

40 Hughes LO, Lahiri A. Improvement in indices of myocardial ischaemia in a case of hypertrophic obstructive cardiomyopathy treated with verapamil. Nucl Med Commun 1987;8:177-82. 